\title{
La realidad de los cuidados a la familia del paciente crítico en España: la necesidad de actuar ya
}

Vemos y no hacemos, describimos y no actuamos, conocemos pero no cambiamos. Esta frase reiterativa describe la naturaleza de muchas situaciones de la práctica enfermera en las que se dispone de una descripción precisa del entorno o contexto en el que se sitúan, de aquello que las personas a las que cuidamos necesitan y de la actuación idónea en estos casos, pero no existe una repercusión en los cuidados enfermeros del día a día.

Esta realidad se refleja, de forma clara, en la progresión de la intervención enfermera con la familia del enfermo crítico en nuestro país. Así, durante las últimas dos décadas, han proliferado estudios relativos a esta temática, denotando un incremento del interés de las enfermeras y enfermeros por la familia en este contexto. Se ha descrito la cultura cerrada de las Unidades de Cuidados Intensivos (UCl) en España ${ }^{1}$, conocemos las vivencias y necesidades de los familiares que tienen a un ser querido ingresado ${ }^{(2,3)}$, sabemos cómo se sienten y qué opinan las enfermeras sobre la familia(4-7), y nos han transmitido, en estudios internacionales mayoritariamente, que una política de visitas abiertas, que la implicación de la familia en el cuidado de la persona ingresada en $\mathrm{UCl}$, y que los cuidados dirigidos a la familia forman parte de la visión holística que caracteriza nuestra manera de cuidar y, además, influyen positivamente en la recuperación del enfermo crítico ${ }^{(8)}$. Sin embargo, después de todos estos estudios, en la mayoría de UCls españolas, la forma de atender a las familias no ha cambiado, o lo ha hecho de forma poco significativa ${ }^{(9)}$.

A pesar de que Zaforteza et al. ${ }^{(9)}$, en el año 2008, ya exponían este problema e instaban a cambiar el foco de la investigación de una tendencia descriptiva a otra intervencionista, desde entonces, se ha avanzado muy poco en este sentido. $Y$ es que a pesar de aparecer, en la actualidad, alguna intervención relacionada con el cuidado a la familia ${ }^{(4,10,11)}$, seguimos sin modificar la estanqueidad de las UCls y la alienación de la familia como parte de la misma. 
En ocasiones, simplemente no modificamos la práctica o no sabemos cómo hacerlo; en otras el cambio se produce a nivel individual o en grupos reducidos sin afectar la organización de la unidad; y en otras realizamos intervenciones pero sin evaluarlas científicamente ni difundirlas, por lo que caen en el ostracismo y no existen para el resto de los profesionales.

La enfermería, como disciplina profesional, además de utilizar otras fuentes de conocimiento, utiliza y produce saber a partir de la experiencia práctica. No obstante, no vale el "hacer porque se ha hecho siempre", no vale instaurarse en la pasividad y la falsa seguridad (o comodidad) del statu quo. Hacerlo nos atrapa en un atolladero donde se ralentiza el avance de la disciplina, o lo que aún es peor, nos impide mejorar la calidad, eficiencia y eficacia de nuestros cuidados.

Por todo ello, es preciso evitar correr el riesgo de convertirnos en estatuas de sal, en autómatas del cuidado estático sin consciencia de nuestro poder para avanzar. Es apremiante utilizar estrategias para modificar de forma dinámica y científica la práctica, es necesario implantar cuidados sistemáticos dirigidos a la familia del enfermo crítico, evaluarlos y modificarlos en base a la evidencia y al contexto en el que se producen. En definitiva, es inexcusable aplazar el cambio. Es apremiante actuar ya.

\section{Bibliografía:}

1. Velasco JM, Prieto JF, Castillo J, Merino N, Perea-Milla E. Organización de las visitas en las unidades de cuidados intensivos en España. Enferm Intensiva. 2005; 16(2):73-83.

2. Hidalgo I, Vélez Y, Pueyo E. Qué es importante para los familiares de los pacientes de una Unidad de Cuidados Intensivos. Enferm Intensiva 2007; 18(3): 106-14.

3. Llamas-Sánchez F, Flores J, Acosta ME, González J, Albar MJ, Macías C. Necesidades de los familiares en una Unidad de Cuidados Críticos. Enferm Intensiva. 2009; 20(2):50-7. 
4. Delgado P, Sola A, Mirabete I, Torrents R, Blasco M, Barrero R et al. Modificación de la práctica enfermera a través de la reflexión: una investigación-acción participativa. Enferm Intensiva. 2001; 12(3):110-26.

5. Zaforteza C, Gastaldo D, de Pedro JE, Sánchez-Cuenca P, Lastra P. The process of giving information to families of critically ill patients: a field of tension. Int J Nurs Stud. 2005; 42:135-45.

6. Marco L, Bermejillo I, Garayalde N, Sarrate I, Margall MA, Asiain MC. Intensive care nurses' beliefs and attitudes towards the effect of open visiting on patients, family and nurses. Nurs Crit Care. 2006; 11(1):33-41.

7. Zaforteza C, García A, Quintana R, Sánchez C, Abadía E, Miró JA. Abrir la unidad de cuidados intensivos a los familiares: ¿qué opinan los profesionales? Enferm Intensiva. 2010; 21(2):52-7.

8. Errasti-Ibarrondo B, Tricas-Sauras S. La visita flexible en las unidades de cuidados intensivos: beneficios para los familiares del paciente crítico. Enferm Intensiva. 2012. Http://dx.doi.org/10.1016/j.enfi.2012.08.001.

9. Zaforteza C, Sánchez C, Lastra P. Análisis de la literatura sobre los familiares del paciente crítico: es necesario desarrollar investigación en cuidados efectivos. Enferm Intensiva. 2008; 19(2): 61-70.

10. Torrents R, Oliva E, Saucedo MJ, Surroca LI, Jover C. Impacto de los familiares del paciente crítico ante una acogida protocolizada. Enferm Intensiva. 2003; 14(2):49-60.

11.Zaforteza C. Promoción de los cuidados dirigidos a los familiares del paciente crítico a través de una investigación-acción participativa. [Tesis]. Palma de Mallorca: Universitat de les Illes Balears. 